\title{
Open Safety Pin in Larynx: A Case Report and Review of Literature
}

\author{
${ }^{1}$ Diptiman Baliarsingh, ${ }^{2}$ Arun Rath, ${ }^{3}$ Ashutosh Hota, ${ }^{4}$ Rajlaxmi Panigrahi
}

\begin{abstract}
A foreign body in the respiratory tract is a serious event, and it needs urgent attention. It is important to know the type of foreign body with careful history taking. Usually, such cases come in pediatric age group due to accidental ingestion or inhalation. We present a case of 12-year-old female who presented with an impacted open safety pin lodged in the larynx. Its sharp end was upward in position and penetrated the subglottis and anterior commissure. A tracheotomy was done for securing airway, and the foreign body was removed with the help of rigid endoscope. The child had an uneventful recovery.
\end{abstract}

Keywords: Foreign body, Larynx, Safety pin, Tracheotomy.

How to cite this article: Baliarsingh $D$, Rath $A$, Hota $A$, Panigrahi R. Open Safety Pin in Larynx: A Case Report and Review of Literature. Int J Otorhinolaryngol Clin 2017;9(1):21-24.

\section{Source of support: Nil}

Conflict of interest: None

\section{INTRODUCTION}

Foreign body impaction or aspiration into the respiratory tract is encountered commonly in the pediatric age group. It is a serious problem and can be a cause of significant morbidity and mortality. Foreign body in the larynx and tracheobronchial tree may lead to respiratory distress and may cause complete occlusion at glottic inlet or tracheal level. They can be lodged in laryngotracheal region or tracheobronchial tree. Various types of foreign bodies are encountered in airway from nostril up to bronchus, which can be organic (vegetative, insect, etc.) or inorganic (metallic or nonmetallic). Safety pins as foreign body are rarely reported in the literature. Further cases of open safety pin directed upward with impaction at glottis region are reported in few literatures.

\footnotetext{
${ }^{1}$ Junior Resident, ${ }^{2,3}$ Assistant Professor, ${ }^{4}$ Professor

1,3,4 Department of Otolaryngology and Head and Neck Surgery $\mathrm{Hi}$-Tech Medical College and Hospital, Bhubaneswar, Odisha, India

${ }^{2}$ Department of Anesthesia, Institute of Medical Sciences \& Sum Hospital, Bhubaneswar, Odisha, India

Corresponding Author: Diptiman Baliarsingh, Junior Resident Department of Otolaryngology and Head and Neck Surgery $\mathrm{Hi}$-Tech Medical College and Hospital, Bhubaneswar, Odisha India, Phone: +91-9438436775, e-mail: diptimanbaliarsingh@ gmail.com
}

\section{CASE REPORT}

A 12-year-old girl while playing with a safety pin in the mouth accidentally swallowed it during forceful inhalation through mouth, which preceded a sudden bout of cough. The child did not communicate to her parents in fear of getting scolded. She had immediately developed stridor, which persisted till she presented to us after 12 hours of ingestion in the outpatient department. She was clinically examined thoroughly; the neck was not manipulated for clinical examination for preventing further penetration of the sharp end of safety pin. During examination, the child was sitting comfortably with no pain in the region of neck. Stridor and hoarseness of voice were present, which raised the suspicion of impaction at glottic inlet. There were no symptoms of respiratory obstruction, and vitals were stable.

An X-ray of soft tissue neck, anterior posterior and lateral view, was advised, which showed a radiopaque shadow of the safety pin in airway, at the level of glottic inlet (Fig. 1). The direction of the safety pin was upward with the blunt end in the laryngeal inlet/rima glottides, and the sharp end was projecting anteriorly toward anterior commissure. The patient was further investigated using a flexible fiberoptic direct laryngoscopy, which showed the clasp of safety pin at glottic inlet area, and the sharp end penetrated the anterior commissure area and was visible from above (Fig. 2).

The patient and her parents were counseled for the procedure to be performed with consent for performing a tracheotomy for removal of the foreign body from larynx. She was planned for removal of foreign body
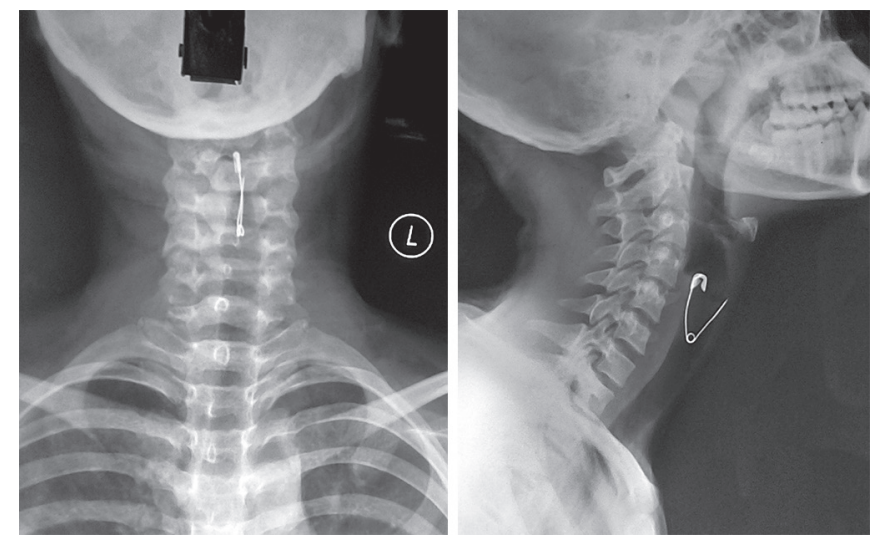

Fig. 1: X-ray neck (AP and lateral view) showing open safety pin in larynx 

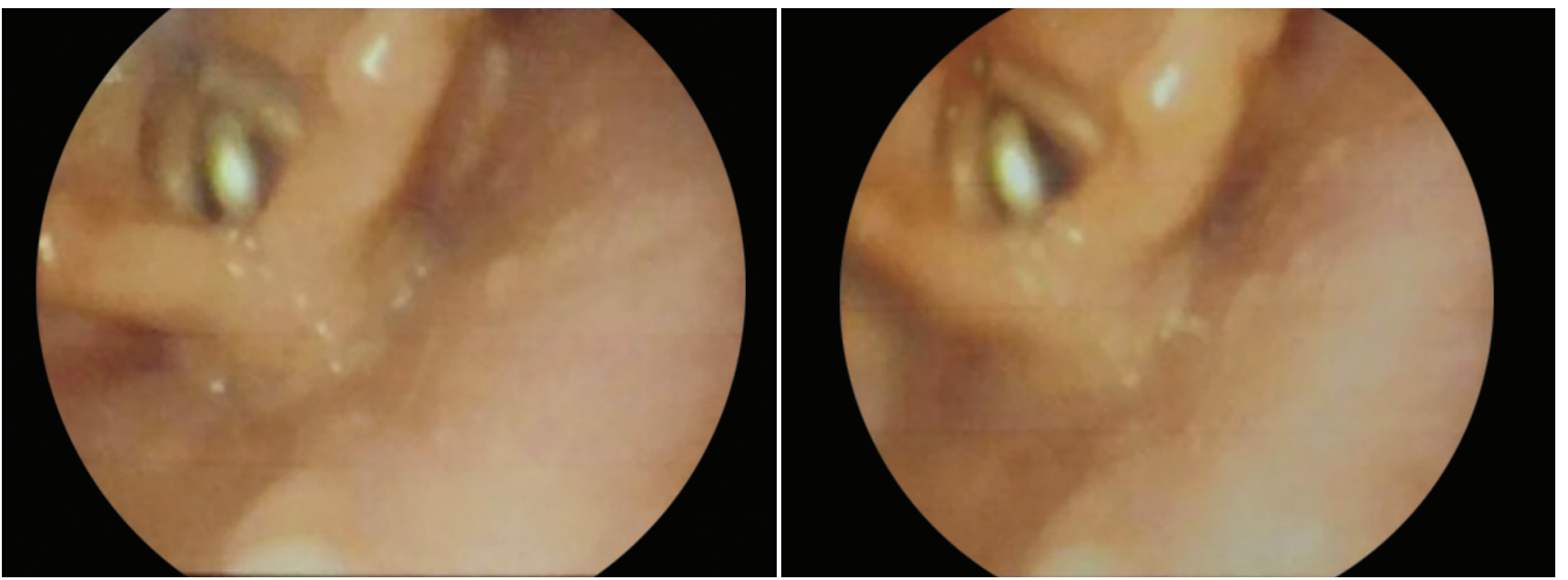

Fig. 2: Flexible Laryngoscopy showing safety pin at laryngeal inlet

under general anesthesia. Patient was premedicated with injection glycopyrrolate $0.1 \mathrm{mg}$ (i.v.), inj. ondansetron $2 \mathrm{mg}$ (i.v.), injection dexamethasone $2 \mathrm{mg}$ (i.v.), and any type of sedatives were avoided as premedication for the fear of respiratory depression. The patient was planned for inhalational induction with sevoflurane and inj. ketamine $0.5 \mathrm{mg} / \mathrm{kg}$ was used as analgesic, spontaneous respiration was maintained without bag and mask assist for the fear of distal migration of the pin. A tracheotomy was performed after infiltration of $2 \%$ lignocaine with adrenaline and intratracheal instillation with $4 \%$ lignocaine and a No. 5.5 flexo-metallic cuffed endotracheal tube was introduced through the tracheostomy. Anesthesia was maintained with sevoflurane, oxygen and nitrous

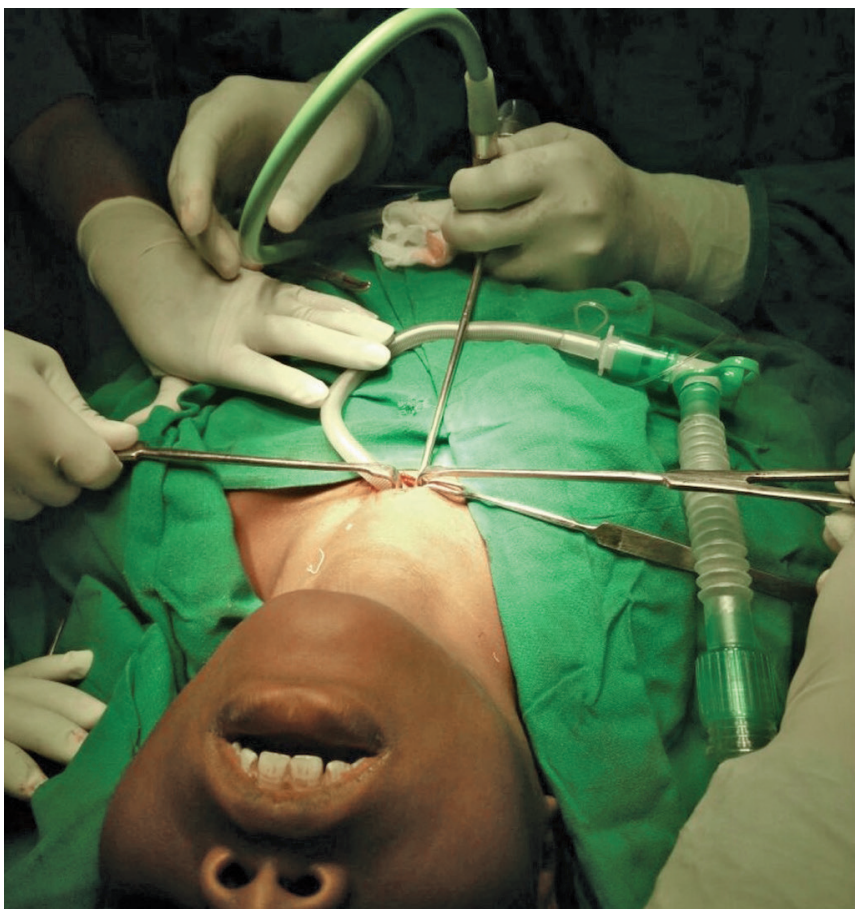

Fig. 3: Intraoperative photograph of endoscopic visualization of safety pin in larynx through tracheostomy oxide mixture, and spontaneous assisted breathing was maintained throughout the procedure. A zero-degree rigid endoscope was used to visualize and confirm the radiological findings through the tracheotomy (Fig. 3). The lower end of safety pin was grasped firmly and was removed with a curved artery forceps under direct vision (Fig. 4). The patient had uneventful recovery from anesthesia. The tracheostomy site was left with a tracheostomy tube in situ and the patient was decannulated on the 2 nd postoperative day.

The patient was advised nebulization with epinephrine and budesonide for the next 48 hours to reduce airway edema. The patient was given intravenous antibiotics, steroids, analgesic, and anti-inflammatory

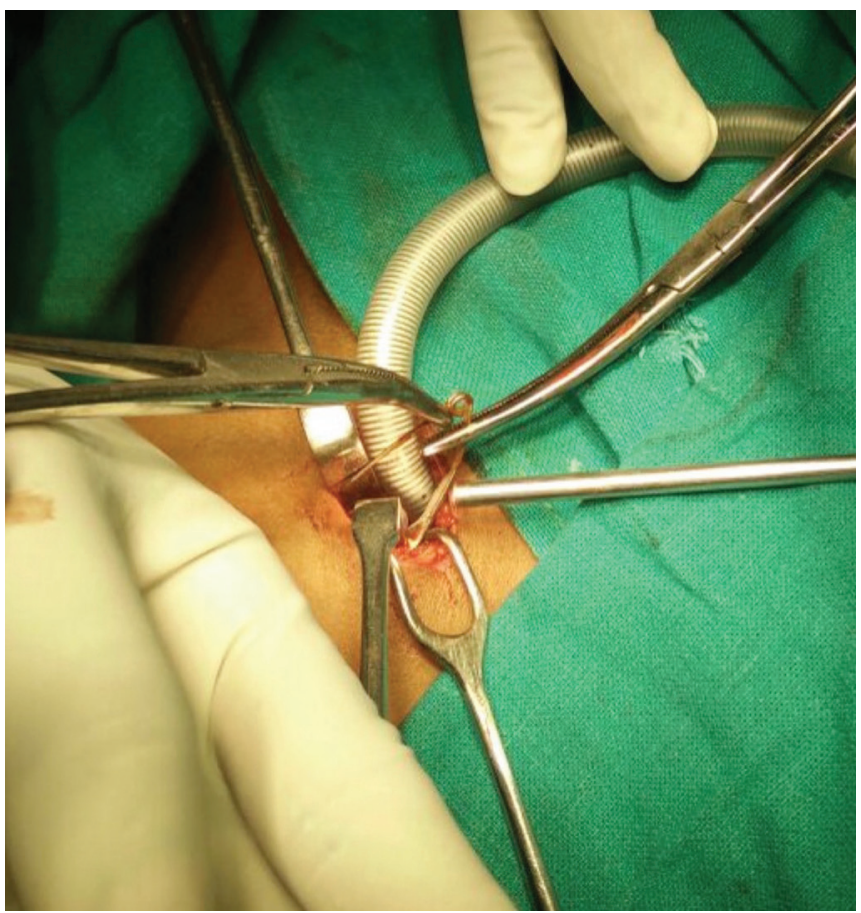

Fig. 4: Intraoperative photograph of removed safety pin from larynx 
drugs along with proton pump inhibitors with prokinetics. Flexible endoscopy was performed after 3 days, which showed normal vocal cord movement. The patient was discharged after 3 days with oral antibiotics and steroids (prednisolone) for a week. The patient was advised to follow-up after 1 month, which showed normal appearance and movement of vocal cords on flexible nasal endoscopy.

\section{DISCUSSION AND REVIEW OF LITERATURE}

Foreign bodies are objects that are foreign to the site where it is located. ${ }^{1}$ A variety of foreign bodies can be encountered in respiratory tract as per published literature, such as peanuts, seeds, fish bones, teeth, broken tracheostomy tubes, coin battery, plastic beads, etc. In one of the literature, Ganguly et $\mathrm{al}^{2}$ reported a case of a 29-year-old female who was diagnosed with a blackcolored leech in glottic chink. Clinical presentation and severity of symptoms depend on location in airway, size and composition of the object, and duration of time for which the foreign body is present.

Although cases present with foreign bodies in ear, nose, and throat, it seems to be accessible and is usually tempting to remove it. In cases with foreign body in nose, without proper illumination, knowledge, and expertise about its management, one should not meddle, which may lead to dislodgement of the object further down into the airway, which may require flexible bronchoscopy or rarely an open approach like thoracotomy for extraction, and lack of these facilities may prove fatal. Specially, in cases with small, uncooperative, crying children, one should be careful not to intervene unless he/she is confident enough to remove it in the first attempt, else it may be sucked into the tracheobronchial tree with a bout of deep breath while the child is crying. Sharp and pointed foreign bodies, such as needles, pin, and safety pin, are particularly dangerous, which can be lodged and penetrate the soft tissue in the respiratory tract to adjacent structures like esophagus, great vessels, etc.

Aspirated metallic foreign bodies account for $4.4 \%$ among children. ${ }^{3}$ Safety pins in particular account for less than $3 \%$ among all the foreign bodies that are found in the tracheobronchial tree, ${ }^{4}$ and $1.5 \%$ is found in esophagus. ${ }^{5}$ Bora et $\mathrm{al}^{6}$ reported three cases of safety pin in airway, in which one case was of a 2.5-year-old boy with a closed safety pin in trachea at the level of T4-T6 and was removed by bronchoscopy under anesthesia. Dasgupta et al, ${ }^{7}$ in their report, presented a case of a 11-month-old female with an open safety pin in larynx with its head projecting down into trachea, its body overriding the laryngeal inlet, and with the pointed end penetrating the posterior pharyngeal wall. It was removed with the help of direct laryngoscopy under general anesthesia. On a similar note, Kumar et $\mathrm{al}^{8}$ reported a case of 12-year-old female with a similar impaction of open safety pin in larynx with head end above vocal cords opposite to epiglottis and the sharp end piercing the subglottis. It was removed with tracheostomy using No. 6 cuffed portex tube, under direct vision of rigid endoscope under general anesthesia. Hussain et $\mathrm{al}^{9}$ reported a case of a 6-month-old infant with an impacted open safety pin in the larynx with the sharp end penetrating the anterior end of left vocal cord. They did not do a tracheostomy for removal of the foreign body. Al-Halfaw $\mathrm{y}^{10}$ in his series of 32 cases of aspiration of special needles among Islamic females came across one case of a 6-year-old girl who aspirated a wide-open safety pin while playing with it. The safety pin head was in the right lower lobe bronchus with the tip directed upward in the midtrachea. It was removed with flexible bronchoscopy under anesthesia. Apart from all the above literature, going to the extreme end of foreign body aspirations and its removal, like the one as reported by Shad and Agarwal, ${ }^{11}$ a broken safety pin that was lodged in the right main bronchus of a 1-year-old female had to be removed by open surgical method by right thoracotomy following several failed attempts by a flexible bronchoscope. Such types of foreign body aspirations are important in anesthetic point of view as they require single lung ventilation by expert anesthetists.

When such a case of open safety pin impacted at laryngeal inlet presents to us, we should not attempt bronchoscopic removal, which may further cause injury to the vocal cords, mucosal lining, etc., giving rise to edema and respiratory compromise in postoperative period necessitating further management. Although mentioned in literature, use of a Clerk-Arrowsmith's safety pin closing forceps is not possible in this case because such case is being done as an emergency procedure, in a pediatric patient with stridor and manipulation is not possible in laryngeal inlet.

\section{CONCLUSION}

Foreign body aspirations are a surgical emergency. Owing to the condition being preventable in most cases, the public, parents of infants, and young children should be educated about consequences of small objects that can be aspirated or ingested by children at home by accident. Young girls and women who use a safety pin, in particular, should be careful about not putting them in the mouth, which may get aspirated by accident. The medical professionals handling such a case of airway emergency in the emergency room should be careful before meddling with a foreign body impacted anywhere in the respiratory tract. Otolaryngologists, being experts in the field, should be called upon before any examination or intervention is done, otherwise a simple foreign body impacted in nostril 
may land up in larynx or tracheobronchial tree, which will add unnecessary morbidity and mortality to the patient already in distress. Anesthetists in particular when dealing with a foreign body in bronchus, especially those with sharp edges, like that of a safety pin or needle, should be prepared for single lung ventilation and/or thoracotomy, in case a need arises for open surgical procedure for removal of foreign body, during preanesthetic medication.

\section{ETHICAL AND HUMANE CONSIDERATIONS}

\section{Ethical Approval}

All procedures performed in studies involving human participants were in accordance with the ethical standards of the institutional and/or national research committee and with the 1964 Helsinki Declaration and its later amendments or comparable ethical standards.

\section{Informed Consent}

Informed consent was obtained from the participant included in the case study.

\section{ACKNOWLEDGMENTS}

Authors acknowledge the entire OT staff for their sincere effort in helping us to carry out the surgery immediately on emergency basis.

\section{REFERENCES}

1. Jackson, C. Bronchoesophagoscopy. Philadelphia: WB Saunders Co; 1951; p. 13-34.

2. Ganguly SN, Reddy NS, Shrestha A, Shah D, Shakya N, Acharya S. Unusual case of laryngeal foreign body. J College Med Sci Nepal 2010;6(1):45-46.

3. Nader S, Soheila N, Fakher R, Hassan A. Foreign body aspirations in infancy: a 20-year experience. Int J Med Sci 2009 Oct; $6(6): 322-328$.

4. Casuey AL, Tallon DS, Miller RC, Warner ET. A reported safety pin requiring thoracotomy - report of a rare case and review. Pediatr Emerg Care 1997;13(6):397-400.

5. Goel HC, Yadav SPS, Kohile GS, Singh J. Oesophageal foreign bodies. Indian J Otolaryngol 1989;18:49-52.

6. Bora H, Bandyopadhyay SN, Basu SK, Sinha R. Play safe with safety pins. Indian J Otolaryngol Head Neck Surg 1999 Aug;51(Suppl 1):39-42.

7. Dasgupta KS, Lanjewar KY, JoshiSV. Safety pin - the UNSAFE foreign body of air passage. Indian J Otolaryngol Head Neck Surg 2006 Oct;58(4):387-388.

8. Kumar A, Dubey KP, Gupta A, Baruah B. Removal of open safety pin in larynx: a challenging event for an otolaryngologist. Online J Health Allied Sci 2013 Nov;12(3):9.

9. Hussain SSM, Raine CH, Caldicott LD, Wade MJ. An open safety pin in the larynx: a case report. J Laryngol Otol 1994 Mar;108(3):254-255.

10. Ahmed Al-Halfawy. Flexible bronchoscopy for the retrieval of aspirated metallic pins: a case series. J Bronchol 2007 Apr;14(2):83-85.

11. Shad R, Agarwal A. Broken safety pin in bronchus-anaesthetic considerations. Indian J Anaesth 2012;56(6):570-571. 